\title{
Teacher Practice Spaces: Examples and Design Considerations
}

\author{
Justin Reich, YJ Kim, Kevin Robinson, Dan Roy, Meredith Thompson, MIT \\ Email: jreich@mit.edu, yjk7@mit.edu, krob@mit.edu, danroy@,mit.edu, meredith@,mit.edu \\ Massachusetts Institute of Technology
}

\begin{abstract}
Teacher practice spaces are learning environments, inspired by games and simulations, that allow teachers to rehearse for and reflect upon important decisions in teaching. Practice-based teacher educators use a variety of approaches to simulation in methods courses and other professional learning opportunities, and existing simulations often attempt to holistically replicate authentic teaching conditions. We extend this work by developing new kinds of practice spaces that do not attempt to fully simulate teaching, but rather offer playful and creative opportunities for novice teachers to develop skills and dispositions valuable for teachers. We summarize six different practice spaces developed through design research, and then articulate a set of design considerations emerging from this work to expand the genre of pedagogies of enactment in teacher professional development.
\end{abstract}

\section{Introduction}

Every great teacher knows that skill development requires practice (Ball \& Forzani, 2009); ironically, teachers themselves have limited opportunities to practice important teaching moves in low-stakes settings. In a comparative study of teachers, social workers and therapists, Grossman and colleagues (2009) conclude that "prospective teachers have fewer opportunities to engage in approximations that focus on contingent, interactive practice than do novices in the other two [helping] professions." Currently, teacher candidates primarily learn in two spaces: Socratic seminar rooms in education schools (or lecture-heavy workshops for in-service professional development) and practicum classrooms. The former affords discussion and the latter affords immersion into the challenges of teaching, but a third space--a practice space--is needed that combines the authenticity of the practicum classroom with the scaffolding of the graduate school seminar room.

In this article, we summarize a set of design experiments creating teacher practice spaces- learning environments inspired by games and simulations where teachers can rehearse for and reflect on important decisions in teaching. These practice spaces build on rich literature and examples of simulation in teacher education. Most of the existing efforts at simulation in teacher professional learning aim for comprehensiveness; they attempt to immerse students in experiences that closely approximate the full complexity of teaching experiences. For instance, the Sposato Graduate School of Education at the Match Charter School has done inventive work with mock teaching among colleagues (Match 2017), and Mursion creates mixed reality simulations where teacher-learners teach mock lessons with virtual student avatars controlled by a remote operator (Mursion, 2017). These examples aim to holistically simulate the complexity of teaching. By contrast, many of the practice spaces in our design experiments do not attempt to recreate the full complexity of teaching. Instead, these projects explore playful mechanics that allow teachers to approximate skills and dispositions that are valuable for teaching without trying to simulate the whole. To borrow an analogy from sports, much of the work in practice-based teacher education has focused on creating scrimmages - experiences that closely model the complete endeavor. In our practice spaces, we have focused on creating drills: activities that facilitate targeted development of useful skills for an activity without trying to recreate the entire activity. Our research into practice spaces explores playful mechanics that allow teachers to learn skills valuable for teaching through pedagogies of enactment.

In what follows, we describe several important lines of research that inform our design efforts: work in practice-based teacher education, pedagogies of enactment, and clinical simulation in teaching. We then summarize research from six of our existing practice spaces in various stages of development, ranging from Baldermath (a bluff the judge game about fractions), to Committee of N (a tarot deck for school design), to TeacherMoments (a handheld teaching simulation app). Finally, we articulate a set of design consideration that emerge from examining the full set of these practice spaces, and offer suggestions for further exploring this promising domain.

\section{Background and context}

A movement towards practice-based teacher education has grown over the last two decades and expanded greatly in the last ten years. The core tenant of this movement is shifting teacher education away from an emphasis on specifying necessary knowledge for teaching towards specifying teaching practices that include 
both knowing and doing (Mcdonald, Kazemi, Kavanaugh, 2013). The word practice takes on multiple meanings in teacher education - practices are the set of activities that teachers employ in their work and practice is the rehearsal and preparation required to expertly deploy those activities in classrooms (Lampert, 2010). Practicebased teacher education emphasizes helping novice teachers learn specific instructional activities (practices) in large part through rehearsing (practicing) them outside the classroom before employing them in the classroom. This approach is often contrasted with teacher-learning experiences in education school classes or school-based professional development, where teacher-learners discuss theory or instructional approaches (or listen to lectures about these topics), but have few opportunities to enact them.

The proper grain size of these practices is debated. Lemov (2010) provides instruction and video coaching on very specific classroom teaching moves, mostly designed to maintain the continuous attention and time-on-task of students. Lampert and Graziani (2009) argue for a broader frame, where instructional activities are as defined activities with a beginning, middle, and end but variable in how they may unfold in differing contexts. Lemov's teaching moves take seconds, Lampert and Graziani's instructional activities unfold over minutes. Also debated is the degree to which these instructional activities should be understood as standardized versus situated: to what extent are their universally better or worse teaching strategies and to what extent does the effectiveness of any given teaching decision depend on contextual factors of setting and students? In frameworks that view good teaching as universal, practice of teaching moves looks like an actor's rehearsal of a scripted scene, where faithful enactment of the defined elements of the scene is the goal (e.g. Match 2017). In frameworks that view good teaching as situated, practice looks more like rehearsal for improvisational theatre, where key tenets of good performance are interpreted differently for different situations (e.g. Self 2015). In our practice spaces, we are biased towards designs that have the potential to accommodate both perspectives.

Teacher educators have developed a variety of approaches for rehearsing instructional practices. Grossman and colleagues (2009) define a three-part framework for learning and apprenticeship in the helping professions (teaching, social work, etc.): representation, decomposition, and approximation. Teacher educators share representations of teaching (their own modeling, examples of lesson plans, videos of teaching), then decompose and highlight important elements (pacing, classroom management strategies, questioning techniques) from those representations. Teacher-learners then approximate these practices by writing up practice lesson plans or teaching mock lessons. The development of strategies for incorporating these approximations in teacher education are sometimes called pedagogies of enactment (Kazemi, Franke, \& Lampert, 2009).

The last decade has seen tremendously productive design research into these pedagogies of enactment. The Core Practices Consortium is a group of teacher educators from multiple disciplines exploring important practices in teaching and new strategies for rehearsing those practices (McDonald, Kazemi \& Kavenaugh, 2013). Kazemi, Franke, and Lampert (2009) define a cycle of enactment where novices participate in lessons with particular instructional activities as students, teacher-learners then analyze this representation and identify strengths and alternative pathways, novices prepare a plan for teaching with the protocol, and then teacherlearners take turns rehearsing their lesson with colleagues acting as students. The Sposato School of Education promotes similar cycles of scripting instructional moves, practicing with colleagues, and then receiving coaching from peers and mentors. Field-mediated experiences are an innovative approach to practice in methods courses, where entire methods classes visit the classrooms of cooperating teachers for immersive coaching experiences with small groups of K-12 students (CITE XXX). Mursion is a mixed-reality medium where teachers practice teaching skills in front a computer monitor with a series of student avatars (Mursion, 2017). The student avatars are controlled as "digital puppets" by a remote actor who can see and hear the teacher through networked video cameras. Dotger (2013) designs clinical simulations, adapted from medial education, for pre-service students. Teacher-learners interact with actors who are trained with the background story and motivations of a parent, student or colleague with some particular problem or dilemma. Through preparation, roleplay, individual reflection, and peer discussion, novice teachers rehearse for challenging situations in lowstakes settings. Self (2016) has adapted these clinical simulations for addressing issues of culturally responsive teaching. From specific teaching moves, to complex instructional activities, to conversations with parents and students, research into pedagogies of enactment shows promising results in helping novice teachers be better prepared with specific techniques and strategies as they begin classroom teaching.

How widely these approaches are adopted is an open question. No comprehensive study measures the adoption of these new practice-based approaches across GSEs or school districts. As perhaps the newest discipline-based field in teacher education, pedagogies of enactment are well-represented in Computer Science teacher education. In the Exploring Computer Science curriculum (Margolis, Google \& Chapman 2015), novice teachers regularly engage in computer science learning activities, create lessons, and teach them with colleagues. In their report on the challenges of teacher education, (TNTP 2015) surveyed teachers in three large districts and found that 17,27 and 38 percent of teachers, respectively, reported practicing teaching as part of 
professional development "sometimes" or "often". In a charter management organization they surveyed, $82 \%$ of teachers reported practice-based professional development happened "sometimes" or "often." Our sense is that adoption of these practices is growing, but still a limited part of most typical teacher-education and in-service professional development programs.

Our practice spaces are inspired by all of this important work into pedagogies of enactment, and our research attempts to expand new genres of approximation and open new directions in pedagogies of enactment. We observe that most efforts at practice in teacher education aim to approximate as completely as possible the experience of teaching a classroom. In many of our practice spaces, we deliberately relax the constraint of attempting to comprehensively recreate teaching in order to create a wider design space for practice activities. Some of our practice spaces are slices of teaching where we abstract away much of the complexity of the classroom in order to focus on some specific dimension, such as our interactive video case studies where teachers encounter short vignettes of difficult teaching circumstances. Others of our practice spaces engage teacher-learners in non-teaching activities that help them develop skills and dispositions that are useful for teaching. Analogies to sports and musical instruction can be helpful. When training young violinists, music teachers often use bow games: silly songs where violin-learners sing and wave their bow with specific motions while maintaining the correct grip on the bow handle. Young soccer athletes play games such as keep-away to develop ball-handling skills. A violinist will never waive her bow maniacally above her head in a recital, and a soccer player will never play keep-away during a match, but these drills isolate particular skills for development that are then re-integrated-ideally with greater competency-into the complex assemblage of the whole activity. Our teacher practice spaces have the same goal, to introduce new kinds of drills into teacher education, and if these drills prove successful, then they could be added alongside discussions of theory, holistic simulation, and field placements in the repertoire of teacher educators.

\section{Designing teacher practice spaces}

Over the past two years, we have used design-based research methods (Easterday, Rees-Lewis, \& Gerber, 2014) to develop a diverse set of practice spaces. In our design process, we typically begin with construct development, where we identify a skill that we want novice teachers to develop and then consider what they skill looks like when expertly deployed in the classroom. We then prototype playful experiences that allow novice teachers to enact these skills or practices. The ideal design team includes a combination of teachers and teacher educators with a deep understanding of the targeted constructs along with game designers who bring encyclopedic knowledge of existing game mechanics. We iteratively improve new practice spaces through frequent playtests among our lab members along with regular lab-based playtests with pre-service teachers, inservice teachers, and teacher educators. We refine our practice spaces and develop curriculum with which to embed them through field tests in teacher preparation programs or in-service teacher professional development. In the projects discussed below, our field test partners include MIT's Scheller Teacher Education Program, West Virginia University, the College of St. Scholastica, Code.org, Exploring Computer Science, Mobile CSP, and the Hartford Magnet School in Connecticut, all of whom provided invaluable feedback on the projects.

Ideally, the design process of each of our practice space projects would lead to development of four components. First, we develop a practice space with a play mechanic encoded in rules, playing cards, or software that are made available through open source software or openly licensed materials (tsl.mit.edu/practice). Second, we develop authoring tools for our practice spaces so that teacher educators can modify our materials, change rules, and create their own scenarios. For a card game, we might make PDF files of cards available so that teacher educators can edit them. For our simulation platform for handheld devices, we aspire to create software authoring tools for teacher educators to create their own scenarios. Third, we create curriculum examples for each practice space; none of our practice spaces are intended to be entirely selfcontained learning experiences. At a minimum, every practice space experience requires some kind of debriefing or reflection experience to be meaningful, and some of our practice spaces benefit from advanced preparation or interleaved periods of play, reflection, learning, and more play. Fourth, we publish scholarly articles that describe the design principles behind our experiences and provide evidence of their efficacy. Below, we summarize the development and research of six very different teacher practice spaces before describing principles that emerge from examining the full set.

\section{Six Example Practice Spaces}

Below we detail six practice spaces. Playable demos, game materials, curriculum suggestions and other resources can be found at tsl.mit.edu/practice. 


\section{Baldermath}

Baldermath is a bluff-the-judge game about teaching fractions (Pershan, Kim, Thompson, \& Reich 2017), codesigned by the author of the MathMistakes.org blog (Pershan, 2017), an online space where teachers discuss interesting errors from math students. To play the game, a judge leaves the room, and four players are given a homework problem taken from a fourth-grade classroom. One contestant is given an actual piece of student work for the problem, completed by a student with an incorrect or incomplete understanding of the problem. This contestant copies the work into her own hand, and then invents a rationale for why the student thought she was correct. The other contestants invent incomplete or incorrect answers to the problem as well as rationales. The judge returns to the room, the contestants roleplay as students and explain their concocted rationales along with details of their (fabricated or real) student work. The judge then guesses which is the "real" student work. As with Balderdash or the Wait, Wait Don't Tell Me News Quiz, guessing correctly is fun for the judge and guessing wrong is fun for the winning contestant.

Math education research shows that novice teachers typically engage in three unhelpful practices when looking at student work: fixating on whether the answer is correct, making assumptions about the demographics or intelligence of the student, and making assumptions about the quality of instruction (Pershan, Kim, Thompson, \& Reich 2017). By contrast, the most useful practices are looking closely at specific details of student work and making inferences and hypotheses about student thinking and understanding. In Baldermath, the game mechanic naturally guides teachers towards engaging these productive practices and eschewing the unhelpful ones; the game is only fun and winnable by thinking carefully about student thinking and representations of that thinking. In debriefing the game experience, facilitators can show teachers how the practices developed playfully during Baldermath can be productively applied to looking at student work in homework and classwork settings.

\section{Metarubric}

Metarubric is a playful examination of the challenges with using rubrics to evaluate complex performance (Kim, Rosenheck \& Reich, In Submission). Participants select a movie by consensus (such as Titanic) and then briefly create movie posters for the movies. Participants then create rubrics for the posters, and take turns using their different rubrics to grade the posters. In a follow-up round, players develop a rubric for the rubrics - the metarubric — and then take turns grading the rubrics themselves. In conversations between rounds, players typically observe that their favorite posters do not necessarily get the highest rubric scores, and that most rubrics undervalue a component of their poster that they felt was important.

In most teachers lived experience, rubric usage unfolds over weeks: projects are developed, rubrics are designed, students do the projects, and teachers grade them with rubrics. In Metarubric, participants go through this cycle several times within an hour. By collapsing the time of this cycle, participants viscerally encounter tensions with the problematic elements of rubrics. By empathizing as learners experiencing how rubric scores imperfectly map onto the worthy qualities of performance assessments, teachers expand their thinking about how to better align the goals of a learning experience with the assessment criteria for performance assessment.

\section{TeacherMoments}

TeacherMoments is a simulation designed for handheld devices, where participants are immersed in short vignettes of teaching life rendered in text, animation or video, and participants respond to "triggers" with text or improvisational audio responses (Owho-Ovuakporie, Thompson, Robinson, \& Reich, In Submission). In liveactor clinical simulations used in teacher education (Dotger, 2013), actors are trained to portray parents or students in a specific situation. Briefing books given to actors include the background of the character and situation, as well as a series of "verbal triggers" that actors are supposed to include in the conversation (such as "You only called me out because you are racist" or "But what will do you when my (autistic) son hugs someone at an inappropriate time?"). Since these actors are meant to create standardized situations, TeacherMoments tests the viability of encoding these interactions entirely in text and video. For instance, Dotger (2013) has developed a series of parent simulations, including one parent upset because a class is too hard; in TeacherMoments, we record six video sequences of an actor playing this parent. Novice teachers participating in the simulation are required to provide improvised audio responses after each recorded conversational turn. In Dotger's live-actor role plays, his four goals for participants are that 1) they experience the interaction as authentic, 2) that the scenario generates a feeling of cognitive disequilibrium, 3) that participants demonstrate an ability to remain calm under pressure, and 4) that they can articulate some element of their teaching philosophy in response to the verbal triggers from actors. Our playtests suggest that these four goals are met within the experience of TeacherMoments, even though our "actor" is pre-recorded rather than live. Given that teachers 
may never meet a parent during their practicum experience, this application of TeacherMoments gives teacherlearners a chance to practice an important dimension of teaching before their induction period.

TeacherMoments is designed so that teacher educators can create different kinds of scenarios and case studies that allows teachers to rehearse different competencies. We have created a series of scenarios that help students address equity teaching practices in Computer Science instruction (Robinson \& Reich, Forthcoming). Integrating culturally responsive pedagogies in computer science classrooms requires attention to curriculum design and classroom practices and routines, but the "last mile" of equitable teaching are the in-the-moment decisions made by teachers. Equity teaching practices that can shape in-the-moment teaching decisions include addressing preparatory privilege (the advantages of experience that many students, especially white and Asian boys, bring to CS classrooms), acknowledging students' intersectional identities, and adopting asset framings. Pedagogies of enactment, such as TeacherMoments simulations, are particularly effective for surfacing what Dotger and Ashby (2010) calls "conditional inclusive ideologies." These are beliefs about equitable teaching that novice teachers espouse in discussions but often fail to act upon in specific circumstances. For instance, in one of our equity scenarios, two students are assigned a paired activity and one student asks to be allowed to move on to more advanced work rather than work with his disengaged partner. Even teachers who articulate concerns about preparatory privilege in general, may choose to be more concerned with providing additional challenging work for the advanced students rather than addressing how his behavior may be marginalizing his partner. We find, following Dotger and Ashby, that pedagogies of enactment and participating in our interactive case studies are effective mechanisms for surfacing teacher's conditionally inclusive ideologies and opening up new conversations about the competing values that shape teacher decision making.

\section{Eliciting Learner Knowledge (ELK)}

Eliciting Learner Knowledge (ELK) is a two-person online game, with one person role playing a teacher and another role playing a student Thompson, Roy, Wong, Reich, \& Klopfer, Forthcoming). In the ELK platform, players have a conversation through a text-based, chat-like interface. This format has two potential advantages over in-person role plays: the transcript of the conversation allows for immediate reflection on specific, documented details in the exchange, and the conversation can occur when two people are not in the same location, as will be increasingly common as more teacher education happens online. Each round of the game focuses on a conceptual topic in science such as chemical reactions, evolution, or energy, or a topic in mathematics such as rational numbers, fractions, and proportions.

At the beginning of the game, each player receives instructions and a brief overview of the game; the person role-playing the teacher receives a learning objective and the person role-playing the student receives a learner profile with details of the conceptions and misconceptions held by the the student being role-played. Players review the profiles, engage in a synchronous 7-minute conversation, and then both players take the same true/ false quiz as if they were the "student". To encourage collaboration and communication between the players, the quiz is scored on 1) how well the student portrays the student profile, and 2) how well the teacher estimates the student's understanding. ELK has two goals: to help preservice and in-service teachers understand questioning strategies and to learn about possible student misconceptions.

\section{Committee of $\mathrm{N}$}

Committee of $\mathrm{N}$ is a design-based card game for exploring education history and policy through school design (Haas, Reich, Feely, Klopfer, 2016). Participants play as consultants charged with designing elements, such as a classroom design or graduation requirements, of a new high school. Each Committee of $\mathrm{N}$ deck includes eight of these design elements, along with different sets of "value cards" representing belief commitments from the fictional new school. Participants work in pairs, and each round they are dealt hands that include one school design element, and then three school values. Values can include purposes of education (e.g. assimilating immigrants or career/college readiness), theories of learning (e.g. behaviorism to constructionism), instructional methods (e.g. apprenticeship or flipped classroom). A pair might be asked to design the bell schedule for a school inspired by behaviorism, committed to vocational education, and enamored of project-based learning. Pairs create four to eight of these design elements, and then join up with several other pairs to create a school out of their elements. Teams then pitch these joint schools to a panel of "school committee" judges.

For many novice teachers heading out into the field for observations, many elements of school seem fixed and immutable. Committee of $\mathrm{N}$ helps novice teachers see that every practice, every fixture, every routine within in a school was designed at some point in history by people who held a set of values, and if we no longer hold those values we can design new school elements with new values. Not every change is equally easyextra-curricular activities can be redesigned easily whereas most communities can only rotate through new school building after several decades--but recognizing that school elements were designed empowers novice 
teachers to imagine how they might be designed anew. Many students adopt the heuristic of describing the "value cards" underlying the practices and fixtures they see in their school observations. The game mechanic underneath Committee of $\mathrm{N}$ is essentially the same mechanic as the Tarot: players create stories about the future guided by a series of arbitrary constraints, and by imaging different possible futures, players can reflect on which futures they would like to try to bring about in the world.

\section{Motivation Station}

Motivation Station is an in-person card game that creates scenarios for novice and experienced teachers to practice applying principles of cognitive science to motivating students. The gameplay mechanic is similar to Apples to Apples. Each round one participant acts as a judge, and draws cards for a particular student and a particular scenario involving a dilemma of student motivation. Other players hold hands of cards with cognitive science-based principles for motivating students, and each round they select which principle they think would best address the scenario. If the judge selects a player's motivation principle, that player then needs to act out how she would use that principle to address the situation. The judges evaluate the effectiveness of the response, creating natural opportunities for discussion and comparison.

\section{Design considerations in teacher practice spaces}

\section{Authenticity versus playfulness}

One useful gradient for analyzing our six practice spaces is the degree to which they approximate authentic teaching practices. In our set of six practice spaces, TeacherMoments is closest to the authentic approximation - it is the least game-like and the most simulation-like. ELK might be quite authentic for a fully online teacher, but for most classroom teachers the scenarios feel authentic but the interface is an artifice. By contrast, a practicing teacher will never need to fabricate incorrect student work as in Baldermath or use a rubric to evaluate rubrics as in Metarubrics. We find in our feedback across playtests of these different environments that typically the closer an activity replicates authentic teaching practice, the less likely it is to feel playful and fun. It may still feel authentic, challenging, and worthwhile, but novice teachers typically do not experience simulation as playful. Releasing the constraint of authenticity opens up an interesting design space, of playful activities where novice teachers do work that is relevant to teaching while not replicating the exact tasks of teaching. The literature of game-based learning gives us many reasons to be optimistic about the potential of including more playfulness in teacher education: the intrinsic motivation offered through play, the freedom to take risks under the guise of projective identities, the opportunity to experiment with new pedagogical commitments or tactics in low-stakes settings, and revealing of the operation of complex systems by modeling elements of those systems in games (Gee, 2007).

\section{Surfacing problems versus scaffolding practice}

Another gradient across our practice spaces is the degree to which participants develop new skills during gameplay. In Metarubric, participants discover all kinds of tensions and dilemmas in the use of rubrics, but the game play does not necessarily scaffold improvements in practice. Our hypothesis is that teachers will improve their assessment practices because they empathize more closely with how students experience rubrics and recognize more deeply the tensions in designing effective rubrics. By contrast, the game development process for Baldermath unearthed a clearly defined construct for looking at student work - with well-defined productive and unproductive practices, and the mechanics of the game naturally guide participants away from unproductive practices and towards productive ones. A simple debrief at the end of the experience may be sufficient for novice teachers to consciously adopted these new practices. Committee of $\mathrm{N}$ doesn't scaffold a teaching practice per se, but participants learn a useful heuristic - the idea of values underlying a school design element - that can help them better understand the constraints of their context. For the practice spaces that surface problems rather than scaffold practice, we hypothesize that other curriculum elements will need to provide scaffolding in developing novice teacher skills, and the games provide empathy and insight. Across our design efforts, we have found that rigorous construct definition — carefully defining the characteristics of effective practice - is essential to creating games or simulations that scaffold particular practices or approaches.

\section{Considering reusable mechanics}

Many of our practice spaces adopt existing game mechanics. TeacherMoments draws on the pedagogy of clinical simulations, Baldermath is a variation on Balderdash, Motivation Station is a variation on Apples to Apples, and Committee of $\mathrm{N}$ is a variation on the Tarot. A key element to both ELK and MetaRubric is the acceleration of time. In MetaRubric, players conduct a full cycle of rubric development and use over minutes 
rather than days or week, in order to more viscerally confront the tensions of rubric use. We imagine that in future practice space design, these kinds of new and estbalished mechanics will be re-used across different variations of practices spaces, and drawing on existing mechanics is a promising approach to rapidly prototyping new practice spaces and exploring the possibilities of the design space.

\section{Role-Playing Students Playfully Builds Empathy}

Our participants generally enjoy the chance to role-play as students. Participants find it challenging and provocative to think like a confused student in Baldermath, or to reflect on how it feels to receive rubric scores on a complex performance in Metarubric, or to take on the role of a student with incomplete understanding in ELK. Role-playing as students allows novice teachers to reflect on the curse of expertise and dimensions of the novice-expert divide, and roleplay builds empathy with confused students, frustrated parents, and teacher colleagues doing their best in the complex circumstances in schools. Playfully exploring new identities, such as a new and vehement commitment to behaviorism in a Committee of $\mathrm{N}$ design round, allows teachers to try on new pedagogical commitments in low-stakes spaces. In our early design work, we thought of student roleplaying as a transactional part of game design: some players role-played as students to help others being teachers. We now think of student roleplaying as an element that is enjoyable and valuable in its own right.

\section{Gathering Evidence of Efficacy}

Lab-based playtests and small field tests of practice spaces are relatively simple to conduct. In most of our playtests, the majority of the data we collect are artifacts of game play along with participants subjective impression of their experience. These are sufficient to iteratively improve the practice spaces, especially in optimizing for playability and fun, but we have only limited evidence of how our practice spaces are actually changing teacher behavior. Gathering this kind of evidence will require deeper partnerships with more teacher education and professional development programs, and greater investment in collecting observational data about teacher practice before and after gameplay. We have conducted some experiments with simpler near-transfer tasks. For instance, in Baldermath playtests we have had participants look at student work using a

Notice/Wonder protocol pre- and post-game play; we then look for evidence that participants notice more interesting and relevant details and make better hypotheses about student thinking after game play. These neartransfer tasks strike a balance between the purely subjective and impressionistic data collection from many of our playtests and the very high hurdles of using in-depth field research to gather evidence of behavioral change. As this line of research matures, we will need to better understand how well the subjective measures we collect during the game design process correlate with measures of actual behavior change - do the practice spaces that teachers tell us they enjoy and found informative or enlightening actually lead to changes in behavior?

\section{Drills and Scrimmages ; Isolated Skills and Complex Assemblages}

Overall, our prototype practice spaces have received a positive response from the teachers and teacher educators who play them. They are playful, engaging, and provocative, and they draw teachers' attention to the details of in-the-moment teaching decisions: as one participant said during a debriefing, "I used to think of good teaching in terms of good and bad lessons. I now think of good teaching in terms of good or bad 15 seconds." We do not intend these practice spaces to replace more immersive approaches to teaching simulations: mock lessons with colleagues and clinical simulations are critical to the future of practice-based teacher education. That said, releasing ourselves from the constraint of authenticity has opened our design space for inventing new kinds of practice-spaces. As Grossman and colleagues (2009) explain, one of the tensions with pedagogies of approximation is how much to approximate. Teaching requires deploying skills simultaneously in a complex assemblage - in a real classroom a teacher is simultaneously watching the clock, evaluating student attentiveness, drawing on knowledge about student relationships and competencies, and making constant decisions about pacing, behavior management, and student agency. Each of these teaching decisions is intimately entangled with the others, so a tension emerges between isolating skills out of the complex assemblage for practice (since the isolated skill is easier to address than the whole assemblage) and recognizing that none of these elements are actually isolated in real classrooms. Our development of new teacher practice spaces has reinforced our confidence in the potential for isolating particular skills. Just as athletes conduct drills to isolate skills that can be integrated back into the complexity of a whole game, we hope that novice teachers will integrate the skills developed in practice spaces back into the complex whole of their teaching practice. To what extent that re-integration actually occurs and teachers actually change their behavior is the most important question for this line of research to next address. 


\section{References}

Ball D. L., Forzani F. (2009). The work of teaching and the challenge for teacher education. Journal of Teacher Education, 60, 497-511

Dotger, B.H. (2013). "I had no idea”: Clinical simulations for teacher development. New York: Information Age Publishing.

Dotger, B., \& Ashby, C. (2010). Exposing conditional inclusive ideologies through simulated interactions. Teacher Education and Special Education, 33(2), 114-130.

Easterday, M., Rees Lewis, D., \& Gerber, E. (2014). Design-based research process: Problems, phases, and applications. In Proc. of International Conference of Learning Sciences (Vol. 14).

Gee, J. P. (2007). What video games have to teach us about learning and literacy. Second edition. New York: Palgrave Macmillan.

Grossman P., Compton C., Igra D., Ronfeldt M., Shahan E., Williamson P. (2009). Teaching practice; A crossprofessional perspective. Teachers College Record, 111(9), 2065-2100

Haas, J., Reich, J., Feely, C., Klopfer, E. (2016, July) Committee of N: A Card Game for School (Re)Design. Presented at the 2016 Games, Learning and Society Conference, Madison, Wisconsin.

Kazemi E., Lampert M., Franke M. (2009). Developing pedagogies in teacher education to support novice teachers' ability to enact ambitious instruction. In Hunter R., Bicknell B., Burgess T. (Eds.), Crossing divides: Proceedings of the 32nd annual conference of the Mathematics Education Research Group of Australasia. (Vol. 1, pp. 12-30). Palmerston North, NZ: MERGA.

Lampert M. (2010). Learning teaching in, from, and of practice: What do we mean? Journal of Teacher Education, 61(1), 21-34.

Lampert M., \& Graziani F. (2009). Instructional activities as a tool for teachers' and teacher educators' learning in and for practice. Elementary School Journal, 109, 491-509.

Lemov D. (2010). Teach like a champion. San Francisco, CA: Jossey-Bass

Margolis, J., Goode, J., \& Chapman, G. (2015). An equity lens for scaling: A critical juncture for Exploring Computer Science. ACM Inroads, 6(3), 58-66.

Match Charter School (2017). Implementing practice-based PD. MatchMinis. Retrieved from https://www.matchminis.org/videos/for-coaches/6/practice-based-professional-development/

McDonald, M., Kazemi, E., Kavanaugh, S.S. (2013) Core practices and pedagogies of teacher education: A call for a common language and collective activity. Journal of Teacher Education, 64(5)

Mursion. (2017) Increasing teacher preparedness and effectiveness. Retrieved from: https://mursion. com/industries/education.html.

Owho-Ovuakporie, K., Thompson, M., Robinson, K., \& Reich, J. (In Submission). Teacher Moments: An online platform for preservice teachers to practice and reflect on parent-teacher conversations.

Pershan, M. (2017) MathMistakes. Retrieved from mathmistakes.org.

Pershan, M. Kim, Y.J., Thompson, M., \& Reich, J. (2017, April) A Design-Based Approach to Developing a Game for Student Work Analysis. Presented at the National Council for Teachers of Mathematics Research Conference, San Antonio, TX.

Robinson, K. \& Reich, J. (Forthcoming) Using Online Practice Spaces to Investigate Challenges in Enacting Principles of Equitable Computer Science Teaching. Proceedings of the 2018 Special Interest Group on Computer Science Education Technical Symposium.

Self, E.A. (2016) Designing and using clinical simulations to prepare teachers for culturally responsive teaching. PhD thesis, Vanderbilt University, Vanderbilt, TN.

Thompson, M., Roy, D., Wong, T., Reich, J., Klopfer, E. (Forthcoming) Moving from diagnosis to understanding students ideas through the game of Eliciting Learning Knowledge (ELK). To be presented at the National Association for Research in Science Teaching, Atlanta, GA.

TNTP (2015). The Mirage: Confronting the hard truth about our quest for teacher development. The New Teacher Project. Retrieved from https://ntp.org/assets/documents/TNTP-Mirage_2015.pdf.

\section{Acknowledgments}

We gratefully acknowledge the support of the Woodrow Wilson National Fellowship Foundation and Google in the development of our practice space research. 